\title{
Analysis of Nanoarchaeum equitans genome and proteome composition: indications for hyperthermophilic and parasitic adaptation
}

\author{
Sabyasachi Das ${ }^{1}$, Sandip Paul ${ }^{1}$, Sumit K Bag ${ }^{1}$ and Chitra Dutta*1,2
}

\author{
Address: ${ }^{1}$ Bioinformatics Centre, Indian Institute of Chemical Biology, Kolkata-700032, India and ${ }^{2}$ Human Genetics \& Genomics Division, Indian \\ Institute of Chemical Biology, Kolkata-700032, India \\ Email: Sabyasachi Das - sabyadas@yahoo.co.in; Sandip Paul - websandip@gmail.com; Sumit K Bag - sumitbag@yahoo.com; \\ Chitra Dutta* - cdutta@iicb.res.in \\ * Corresponding author
}

Published: 25 July 2006

BMC Genomics 2006, 7:186 doi:10.1186/147|-2164-7-186

This article is available from: http://www.biomedcentral.com/147/-2/64/7/I86

(C) 2006 Das et al; licensee BioMed Central Ltd.

This is an Open Access article distributed under the terms of the Creative Commons Attribution License (http://creativecommons.org/licenses/by/2.0), which permits unrestricted use, distribution, and reproduction in any medium, provided the original work is properly cited.
Received: 30 May 2006

Accepted: 25 July 2006

\begin{abstract}
Background: Nanoarchaeum equitans, the only known hyperthermophilic archaeon exhibiting parasitic life style, has raised some new questions about the evolution of the Archaea and provided a model of choice to study the genome landmarks correlated with thermo-parasitic adaptation. In this context, we have analyzed the genome and proteome composition of $N$. equitans and compared the same with those of other mesophiles, hyperthermophiles and obligatory host-associated organisms.

Results: Analysis of nucleotide, codon and amino acid usage patterns in $N$. equitans indicates the presence of distinct selective constraints, probably due to its adaptation to a thermo-parasitic life-style. Among the conspicuous characteristics featuring its hyperthermophilic adaptation are overrepresentation of purine bases in protein coding sequences, higher GC-content in tRNA/rRNA sequences, distinct synonymous codon usage, enhanced usage of aromatic and positively charged residues, and decreased frequencies of polar uncharged residues, as compared to those in mesophilic organisms. Positively charged amino acid residues are relatively abundant in the encoded gene-products of $N$. equitans and other hyperthermophiles, which is reflected in their isoelectric point distribution. Pairwise comparison of 105 orthologous protein sequences shows a strong bias towards replacement of uncharged polar residues of mesophilic proteins by Lys/Arg, Tyr and some hydrophobic residues in their Nanoarchaeal orthologs. The traits potentially attributable to the symbiotic/parasitic life-style of the organism include the presence of apparently weak translational selection in synonymous codon usage and a marked heterogeneity in membrane-associated proteins, which may be important for $N$. equitans to interact with the host and hence, may help the organism to adapt to the strictly host-associated life style. Despite being strictly host-dependent, $N$. equitans follows cost minimization hypothesis.

Conclusion: The present study reveals that the genome and proteome composition of $N$. equitans are marked with the signatures of dual adaptation - one to high temperature and the other to obligatory parasitism. While the analysis of nucleotide/amino acid preferences in $N$. equitans offers an insight into the molecular strategies taken by the archaeon for thermo-parasitic adaptation, the comparative study of the compositional characteristics of mesophiles, hyperthermophiles and obligatory host-associated organisms demonstrates the generality of such strategies in the microbial world.
\end{abstract}




\section{Background}

The hyperthermophilic archaeon Nanoarchaeum equitans is characterized by several intriguing features. It is the only known parasitic archaeon and for survival it must be in contact with the crenarchaeon host Ignicoccus. Its genome size is only $490 \mathrm{~kb}$, representing the smallest microbial genome known to date, and yet it has the highest coding density, encoding for 536 genes [1]. Phylogenetic analyses suggested that this microbe is probably a derived, but genomically stable parasite diverged anciently from the archaeal lineage [2].

The genes for several vital metabolic pathways appear to be missing in Nanoarchaeum [1]. This could be due to two plausible reasons. $N$. equitans might represent an ancient species, and hence possesses a small genome. Alternatively, it might have gone through a process of genome reduction as a strategy of adaptation to the obligatory parasitic lifestyle, as observed in cases of many other parasitic/symbiotic organisms [1]. However, in obligatory intracellular bacteria, many genes involved in DNA recombination and repair along with the biosynthetic and metabolic genes are usually lost $[3,4]$. But $N$. equitans possesses most of the DNA repair enzymes and the complete genetic machinery necessary for transcription, translation and DNA replication. The complexity of its information processing systems and the simplicity of its metabolic apparatus, therefore, suggest the presence of an unanticipated world of organisms yet to be characterized.

Most of the obligatory symbiotic/parasitic bacteria are characterized by the presence of only one/two rRNA operons, a small number of genes for tRNA isoacceptors, slow growth rate and an overall AT-richness [5-7]. It has been proposed that at the beginning of the symbiotic or parasitic integration, the loss of the genes involved in DNA repair favored the bias toward $\mathrm{A}+\mathrm{T}$ content of such genomes $[3,4,8]$. However, the presence of a full set of archaeal DNA repair and recombination enzymes in $N$. equitans [1] contradicts the established hypothesis regarding AT-richness of its genome. Evidences for apparently little or no translational selection in synonymous codon usage have been reported for most of the species with reduced genomes examined so far, such as Borrelia burgdorferi [9], Buchnera aphidicola [10], Helicobacter pylori [11], Bartonella [12], Wigglesworthia [13] and Tropheryma whipplei [14] etc. Some of these bacteria exhibit strong base compositional asymmetries between leading and lagging strands of replication. It was, therefore, of interest to investigate whether N. equitans, an archaeon, is also characterized by any of such typical traits of the reduced genomes.

The composition of N. equitans genome and proteome are expected to bear the signatures not only of parasitism, but also of hyperthermophilicity. Comparative analysis of complete genomes of several hyperthermophilic archaea and bacteria revealed that organisms adapted to high temperature require a coordinated set of evolutionary changes towards stability of mRNA, codon-anticodon interactions [15], increased thermostability of encoded proteins by van der Waals interactions [16], larger number of residues in the alpha-helical conformation [17], enhanced secondary structure propensity [18], higher core hydrophobicity [19], additional networks of hydrogen bonds [20], increased ionic interactions [21], increased packing density [22], decreased length of surface loops [23] etc. With increase in growth temperature, microbial organisms tend to acquire base $\mathrm{A}$ and lose base $\mathrm{C}$ while keeping the contents of bases $\mathrm{T}$ and $\mathrm{G}$ relatively constant [24], and there is a clear link between a particular pattern of codon usage and the elevated growth temperature [25].

The current report presents an extensive study on the genome and proteome composition of $N$. equitans, along with a comparative analysis of the compositional characteristics of other mesophiles, hyperthermophiles and obligatory host-associated organisms. Only A+T -rich organisms were selected for analysis, so that the inter-species differences in nucleotide/amino acid usage patterns due to mutational bias could be minimized and any difference in such usage patterns among the mesophilic and hyperthermopilic organisms could be fairly attributed to their adaptation to the growth temperature. The study provides a more detailed view on the genome-wide strategies employed by N. equitans for adaptation to the hyperthermophilic environment and parasitic life style.

\section{Results \\ Nucleotide preferences in protein-coding genes and structural RNA sequences}

We have analyzed the annotated open reading frames (ORFs) and the tRNA and rRNA sequences separately in $N$. equitans and other organisms with a view to scrutinizing the trends in nucleotide selection and their relevance to the lifestyle of the organism. Table 1 presents the base composition of the ORFs and structural RNA sequences of the fifteen organisms under study. The frequency distributions of the ORFs of $N$. equitans and other hyperthermophiles exhibit a significant $\left(\mathrm{p}<10^{-7}\right)$ shift towards higher purine content as compared to those of the mesophiles for both non-synonymous and synonymous codon positions (Fig. 1a, b). As expected, there is a strong positive correlation $\left(\mathrm{r}=0.89, \mathrm{p}<10^{-4}\right)$ between the overall purine-pyrimidine ratio $(\mathrm{R} / \mathrm{Y})$ of ORFs and the optimal growth temperature (OGT). This suggests that the higher the OGT, the higher is the selection for purine nucleotides in coding sequences (Fig. 1c). 
Table I: General features of the N. equitans genome and I4 other microbial genomes under study

\begin{tabular}{|c|c|c|c|c|c|c|c|c|c|}
\hline & \multirow[t]{2}{*}{ Organism } & \multirow{2}{*}{$\begin{array}{l}\text { Accession } \\
\text { No. } \\
\text { (GenBank) }\end{array}$} & \multirow[t]{2}{*}{ Size (Mb) } & \multirow{2}{*}{$\begin{array}{l}\text { Optimal } \\
\text { growth } \\
\text { temp }{ }^{\circ} \mathrm{C}\end{array}$} & \multirow{2}{*}{$\begin{array}{l}\text { ORFs under } \\
\text { study }\end{array}$} & \multicolumn{4}{|c|}{ GC- content (\%) } \\
\hline & & & & & & Genome & ORFs & rRNAs & tRNAs \\
\hline \multirow[t]{8}{*}{ Hyperthermophilic } & Aquifex aeolicus & AE000657 & 1.59 & 96 & 1485 & 43.3 & 43.7 & 64.8 & 68.4 \\
\hline & Methanocaldococcus jannaschii & $\underline{\mathrm{L} 77117}$ & 1.74 & 85 & 1534 & 31.3 & 32.0 & 63.8 & 66.5 \\
\hline & Nanoarchaeum equitans & AE017199 & 0.49 & 90 & 487 & 31.5 & 31.2 & 66.2 & 72.5 \\
\hline & Pyrococcus abyssi & AL096836 & 1.77 & 96 & 1686 & 44.6 & 45.2 & 65.9 & 70.5 \\
\hline & Pyrococcus furiosus & AE009950 & 1.91 & 96 & 1845 & 40.7 & 41.2 & 66.3 & 70.5 \\
\hline & Pyrococcus horikoshii & BA00000I & 1.74 & 96 & 1717 & 41.8 & 42.3 & 63.2 & 70.7 \\
\hline & Sulfolobus solfataricus & AE006641 & 2.99 & 80 & 2741 & 35.7 & 36.5 & 62.1 & 67.3 \\
\hline & Sulfolobus tokodaii & $\overline{\mathrm{BA} 000023}$ & 2.69 & 80 & 2558 & 32.7 & 33.6 & 63.8 & 67.4 \\
\hline \multirow[t]{7}{*}{ Mesophilic } & Acinetobacter sp. & CR54386I & 3.60 & 37 & 3020 & 40.4 & 41.3 & 51.7 & 58.1 \\
\hline & Bacillus subtilis & AL009126 & 4.21 & 35 & 3615 & 42.0 & 43.9 & 54.2 & 58.5 \\
\hline & Listeria innocua & AL592022 & 3.09 & 37 & 2677 & 37.0 & 37.8 & 52.8 & 58.23 \\
\hline & Methanococcus maripaludis & BX950229 & 1.66 & 37 & $|54|$ & 33.1 & 34.1 & 54.2 & 61.2 \\
\hline & Methanosarcina acetivorans & AE010299 & 5.75 & 37 & 3958 & 42.6 & 45.4 & 54.5 & 60.5 \\
\hline & Methanosarcina barkeri & $\overline{\mathrm{CP} 000099}$ & 4.87 & 37 & 3206 & 39.2 & 42.4 & 53.6 & 59.5 \\
\hline & Methanosarcina mazei & AE008384 & 4.10 & 37 & 2986 & 41.4 & 44.4 & 54.2 & 60.7 \\
\hline
\end{tabular}

While the predicted ORFs of hyperthermophiles are characterized by overrepresentation of purine content, the structural RNA genes of $N$. equitans and other hyperthermophiles exhibit much higher GC-content than those of the mesophiles (Table 1). The GC-content of tRNA/rRNA genes exhibit a strong positive correlation $(r=0.98$ and 0.96 at $\mathrm{p}<10^{-4}$ for rRNA and tRNA respectively) with the optimal growth temperature (OGT) (Fig. 1d). Similar observation has been reported earlier in thermophilic prokaryotes $[26,27]$. The higher GC-content of non-coding RNA sequences in N. equitans and other hyperthermophiles could be a strategy to facilitate the intramolecular stabilization of RNA secondary structure at elevated temperature. This notion is in agreement with earlier reports $[28,29]$ demonstrating a significant correlation between the growth temperature and the GC-content of 16S rRNA, which is shown to be strongest in the double-stranded stem regions of the rRNA.

In order to evaluate purine richness in protein coding sequences, we have calculated the Chargaff differences in nucleotide composition (a measure of purine-loading) for the entire genome. Like other hyperthermophilic prokaryotes [24], N. equitans strictly follows Szybalski's transcription direction rule in spite of its obligatory parasitic lifestyle. The purine-pyrimidine skew correlates strongly with the location of the ORFs in two strands (Fig. 2) and therefore, the ORFs residing in the direct strand as well as those in the complementary strand, in general, tend to be purine-rich. It was proposed earlier that the selection for purine-rich mRNA sequences in thermophilic organisms may minimize unnecessary RNA-RNA interactions and prevent double-strand RNA formation within the molecule [30]. The purine-loading in the coding sequences of $N$. equitans, therefore, may be attributed to its adaptation to high temperature. The GC-content of predicted ORFs or the purine content of structural RNA sequences does not exhibit any significant correlation with the optimal growth temperature of the organisms under study.

\section{Global analysis of proteome composition}

Correspondence analysis (COA) has been carried out on amino acid usage of the 35056 predicted gene-products of the fifteen organisms under study (Table 1) to find out the interproteomic variation in amino acid composition, if any. The analysis reveals that the mesophiles and hyperthermophiles are clearly segregated on positive and negative sides of axis 3, which represents $10.6 \%$ of total variation (Fig. 3a). Thus amino acid usage patterns follow distinct trends in hyperthermophilic (including N. equitans) and mesophilic organisms irrespective of the phylogenetic relatedness, supporting previous observations $[15,31]$. The encoded proteins in thermophiles are characterized by an increase in frequency of charged amino acid residues and a decrease in that of polar uncharged residues as compared to the mesophilic counterparts $[32,33]$. However, a discrepancy is noticeable in the overrepresentation of positively and negatively charged residues in hyperthermophilic proteins. The percentage of proteins having positively charged to negatively charged amino acid ratio $(\mathrm{P} / \mathrm{N})>1$ is significantly high in hyperthermophiles compared to mesophiles. A strong positive cor- 

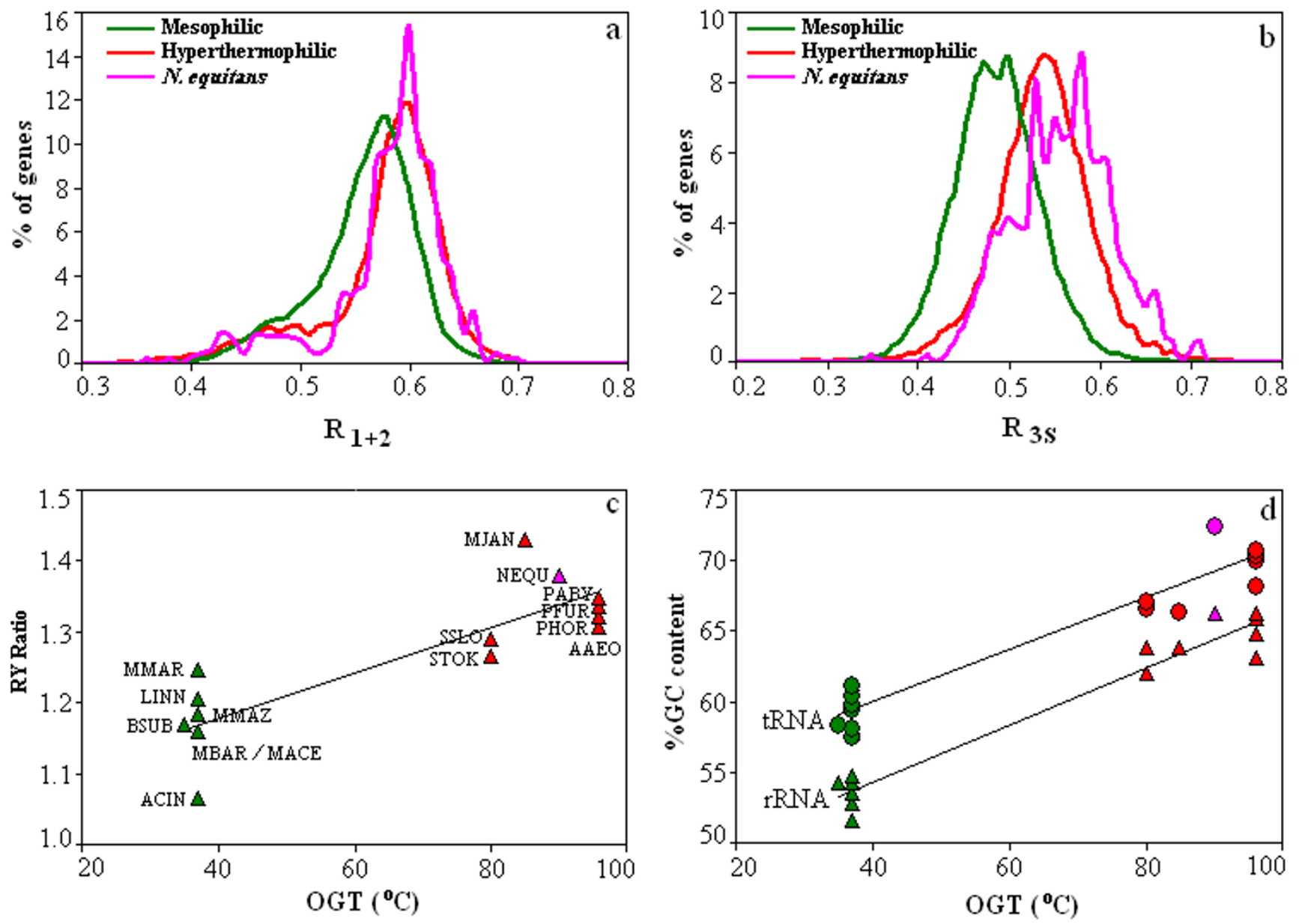

Figure I

Distribution of genes on the basis of purine content at (a) nonsynonymous codon positions $\left(R_{I+2}\right)$; (b) synonymous codon positions $\left(R_{3 S}\right)$ for seven mesophiles (Green line), seven hyperthermophiles (Red line), and N. equitans (Pink line). (c) Relationship between optimal growth temperature (OGT) and average Purine-pyrimidine ratio (RY ratio) of protein coding sequences. (d) Relationship between optimal growth temperature (OGT) and average GC-content of structural RNA sequences. The green, red and pink colors represent mesophiles, hyperthermophiles and $N$. equitans respectively. The filled circles for tRNAs and the filled triangles for rRNAs.

relation $\left(\mathrm{r}=0.88, \mathrm{p}<10^{-5}\right)$ exists between the OGT of the organisms and the percentage of proteins having $\mathrm{P} / \mathrm{N}$ ratio greater than one in the respective proteomes (Fig. $3 \mathrm{~b}$ ).

Overrepresentation of positively charged residues in the gene-products of $N$. equitans and other hyperthermophiles is also apparent from Fig. 3c, which shows the predicted isoelectric point (pI) distribution of the proteins of the fifteen organisms under study. A bimodal distribution of isoelectric points is observed with an acidic peak at pI range of 5.0-5.5 and a basic peak at $~ 9.5$. For the mesophiles, the acidic peak is much larger than the basic peak, while the reverse is the case for hyperthermophiles. For $N$. equitans, the number of basic proteins is even appreciably higher than that observed with other hyperthermophiles (Fig. 3c). These results suggest that the hyperthermophilic proteomes are characterized by a relative predominance of basic proteins. In addition to the relative abundance of positively charged residues, the frequency distribution of the encoded proteins of $N$. equitans and other hyperthermophiles is also shifted significantly $\left(\mathrm{p}<10^{-7}\right)$ towards higher aromaticity, as compared to that of the mesophiles (Fig. 3d).

\section{Comparison with mesophilic orthologs}

The pairwise comparison of 105 protein sequences from $N$. equitans and their homologs from seven mesophilic organisms under study shows that there has been a signif- 


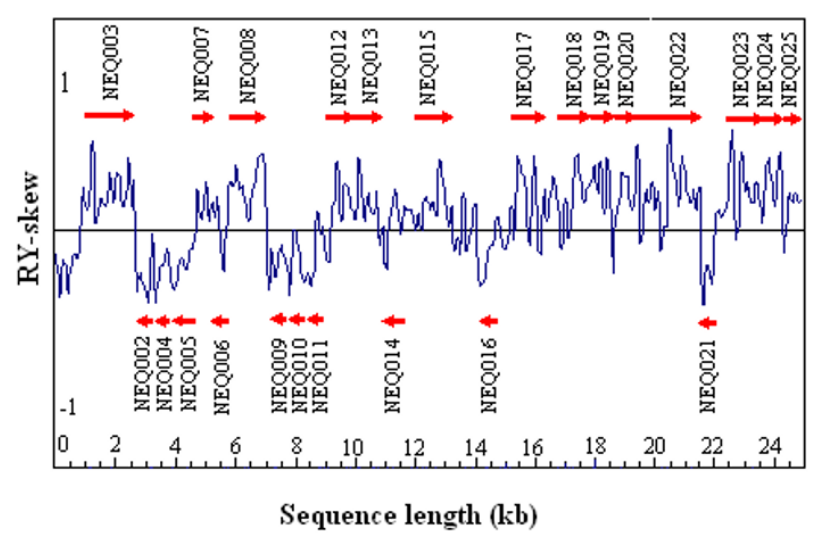

Figure 2

Plot of purine-pyrimidine (R-Y) skew along the first $25 \mathrm{~kb}$ of the genomic sequence of $N$. equitans. The locations of putative ORFs are shown as red arrows (upper arrows for ORFs present in direct strand; lower arrows for ORFs present in complementary strand).

icant increase in frequencies of positively charged residues (but not of overall negatively charged residues) in N. equitans proteins (Table 2). Among negatively charged residues, Glutamic acid but not Aspartic acid, is used with increased frequency in hyperthermophiles. Furthermore, there are significant increases in aromaticity and average hydrophobicity (calculated using Sweet and Eisenberg scale) [34] and a decrease in the usage of polar uncharged amino acid residues (Ser, Thr, Gln and Asn) in the N. equitans gene-products (Table 2). Previous studies on thermoadapted organisms reported a trend for increase in number of overall charged residues [32,33]. But the present analysis clearly indicates that among the charged residues, frequencies of the positively charged residues increase significantly.

In order to get a better insight into such trends, we have determined the frequencies of all possible amino acid replacements (i.e., $[20 \times 19] / 2=190$ possible pairs of replacements) between the orthologous sequences in the direction of mesophiles to N. equitans [see Additional file 1]. Table 3 shows the ratios of the number of observed forward and reverse replacements for each pair of residues in the direction from mesophiles to N. equitans. There are 36 pairs of amino acids ( $20 \%$ of all pairs) that have a significant directional replacement bias $(\mathrm{p}<0.01)$ and they contribute 6,347 of the 16,614 observed replacements (38\% of the replacements). Several of these frequently observed amino acid replacements (i.e., Leu $\rightarrow \mathrm{Ile}$, Val $\rightarrow$ Leu, Met $\rightarrow$ Ile etc.) are conservative and have already been reported $[32,35]$. It is worth mentioning that some of the apparently high values of the ratios of replacements may not have much impact on thermal adaptation of proteins, as the actual number of replacements is too small. For example, for Cys $\rightarrow$ Leu, the high value $(=7)$ of the forward to reverse replacement ratio may not have any structural significance as the number of replacements in the forward (Cys $\rightarrow$ Leu) and reverse (Leu $\rightarrow$ Cys) directions are only 14 and 2 respectively [see Additional file 1]. The analysis shows that in N. equitans, the uncharged polar residues of mesophilic proteins have undergone massive replacement by positively charged residues (especially Lys), aromatic residues (especially Tyr) and some hydrophobic residues (e.g. Ile, Leu etc.), but the replacements in the reverse direction are not so frequent. The highly biased directionality of such amino acid replacements suggests that the favored residues in $N$. equitans proteins may have significant contribution to enhancement and/or maintenance of thermostability.

\section{Surface charge distribution}

In order to examine the structural implications, if any, of higher usage of the positively charged residues in N. equitans proteins, appropriate representatives of orthologous pairs have been selected for homology modeling. Modeled structures have been generated for the elongation factor Tu (EF- Tu) protein of N. equitans (NEQ082), along with the cell division cycle (CDC) family protein from $N$. equitans (NEQ475) and M. maripaludis (MMP0176). The surface charge has been determined for each protein using Coulomb charge calculation. The comparison between $N$. equitans EF- Tu and E. coli EF- Tu [36] and between the CDC proteins from N. equitans (NEQ475) and M. maripaludis (MMP0176) reveals a marked increase in positive charge in the surfaces of the N. equitans proteins as compared to their mesophilic counterparts (Fig. 4). The overall surface charge of $N$. equitans EF-Tu is -2 , while that of its E. coli homolog is -16 . The N. equitans CDC exhibits a surface charge of -2 , while that for its $M$. maripaludis homolog is -20 . These findings are consistent with the higher isoelectric points and higher frequencies of positively charged residues in N. equitans homologs. In EF-Tu of $N$. equitans ( $\mathrm{pI}=7.85)$, the cumulative frequency of $\operatorname{Arg}$ and Lys is $13.2 \%$, whereas in E. coli EF-Tu (pI = 5.30), it is $11.8 \%$. The frequencies of positively charged residues for the CDC homologs NEQ475 (pI = 7.55) and MMP0176 $(\mathrm{pI}=5.19)$ are $16.8 \%$ and $14.5 \%$ respectively. Higher usage of positively charged residues in N. equitans proteins results in an increase in positive charge on their surfaces as compared to their mesophilic homologs.

\section{Intraproteomic variations in amino acid usage}

To understand the trends in amino acid usage of the encoded proteins in N. equitans, COA has been performed on the amino acid composition. Mean aromaticity, hydropathy, aliphatic index and gene expressivity are the major sources of intra-proteomic variations in N. equitans, as indicated by the COA on amino acid usage of the 

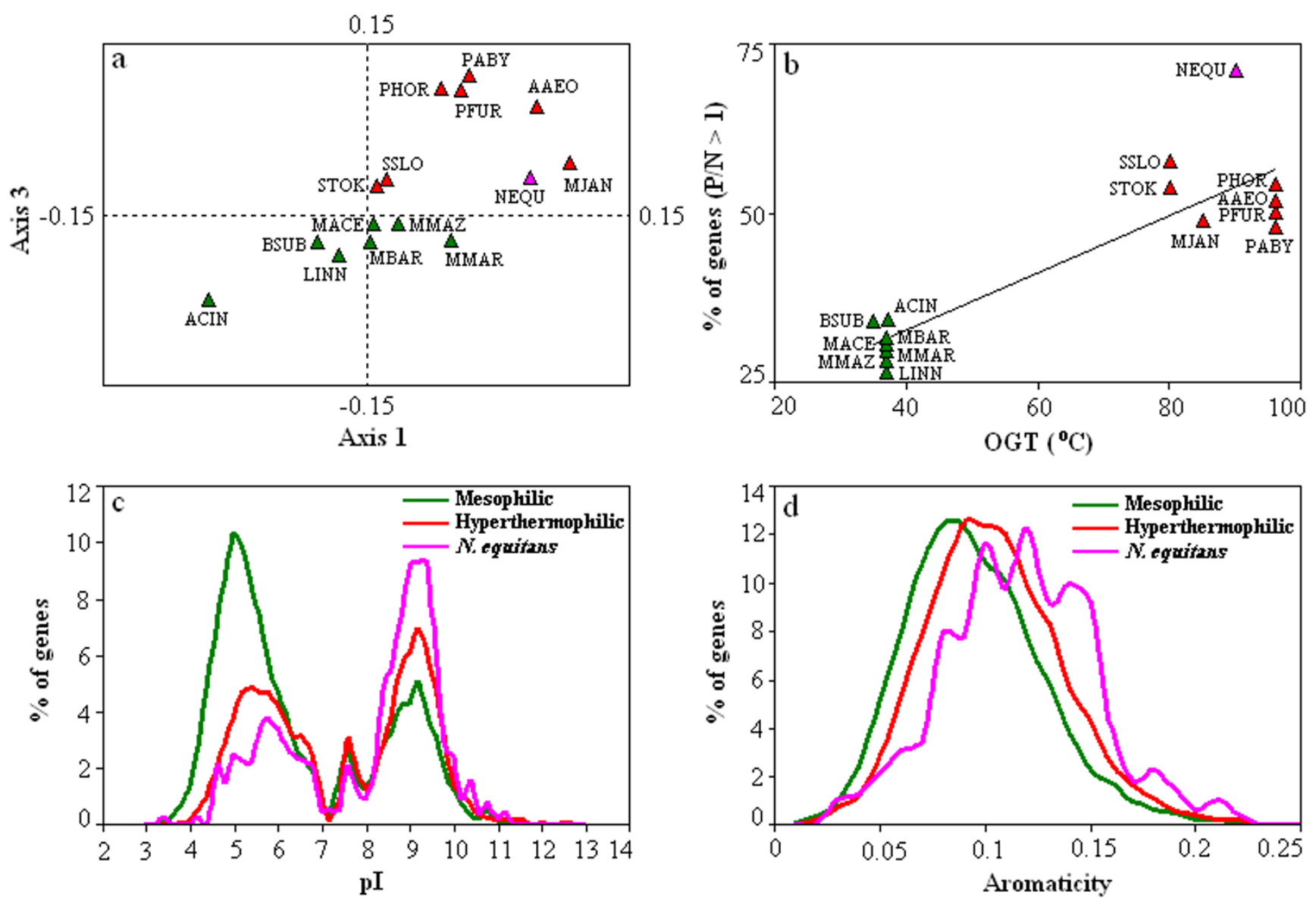

Figure 3

(a) Positions of seven mesophiles, seven hyperthermophiles and $N$. equitans on the plane defined by first and third axes generated from COA on amino acid usage of encoded proteins. (b) Relationship between optimal growth temperature (OGT) of the organisms and the number of genes having ratio of positively charged and negatively charged residues greater than one (P/N ratio $>$ I) in the encoded proteins of respective organisms. (c) Plot for the distribution of genes versus predicted isoelectric point ( $\mathrm{pl}$ ) of encoded proteins. (d) Distribution of genes on the basis of aromaticity of encoded proteins. Green color indicates mesophiles, red color indicates hyperthermophiles and pink color indicates $N$. equitans.

Table 2: Differences between various indices of $N$. equitans proteins and theirmesophilic orthologs

\begin{tabular}{cccc}
\hline Indices & N. equitans proteins & Mesophilic proteins & P \\
\cline { 2 - 3 } & Mean & Mean & $1.7 \times 10^{-11}$ \\
\hline $\begin{array}{c}\text { Average Hydrophobicity (Sweet \& } \\
\text { Eisenberg) }\end{array}$ & 0.015 & -0.056 & 0.32061 \\
Average Hydrophobicity (Kyte \& & -0.349 & -0.313 & $4.2 \times 10^{-9}$ \\
Doolittle) & 0.088 & 0.067 & $2.1 \times 10^{-3}$ \\
Aromaticity Index & 1.391 & 1.135 & $3.0 \times 10^{-6}$ \\
P/N Ratio & 17.1 & 14.5 & 0.31684 \\
Positively Charged Residues (\%) & 13.7 & 13.3 & $1.4 \times 10^{-5}$ \\
Negatively Charged Residues (\%) & 8.332 & 7.158 & $1.1 \times 10^{-13}$ \\
Isoelectric Point & 13.7 & 16.9 & \\
Polar Uncharged Residues (\%) & &
\end{tabular}


Table 3: Trends in amino acid replacements in N. equitans proteins and their mesophilic orthologs

\begin{tabular}{|c|c|c|c|c|c|c|c|c|c|c|c|c|c|c|c|c|c|c|c|c|c|}
\hline & \multicolumn{21}{|c|}{ N. equitans amino acid } \\
\hline & & $\operatorname{Arg}$ & Lys & Glu & Asp & Trp & lle & Pro & Leu & Val & Phe & Tyr & Met & His & Ala & Gly & Cys & Thr & Asn & Gln & Ser \\
\hline \multirow[t]{20}{*}{ Mesophilic homologs amino acid } & Ser & 1.34 & $2.83^{*}$ & $2.47^{*}$ & 2.02 & - & $3.07^{*}$ & 2.65 & 2.30 & 2.43 & 3.33 & 2.55 & 2.44 & 0.81 & 1.35 & 1.13 & $0.14+$ & 1.04 & 1.57 & 1.64 & 1.00 \\
\hline & Gln & 1.52 & $1.56 *$ & 1.03 & 0.75 & 1.50 & $3.86 *$ & 2.18 & 2.13 & 0.74 & 1.00 & 2.60 & 1.21 & 1.20 & 0.72 & 0.55 & 0.00 & $0.29+$ & 1.17 & 1.00 & \\
\hline & Asn & 1.02 & $1.67^{*}$ & 0.87 & 0.96 & 2.00 & 1.71 & 0.91 & 1.14 & 0.65 & 0.54 & $3.00 *$ & 2.00 & 1.13 & 0.54 & 0.78 & 0.67 & 0.77 & 1.00 & & \\
\hline & Thr & 1.33 & $2.38^{*}$ & 1.91 & 1.00 & 4.00 & $2.23^{*}$ & 2.35 & $2.72^{*}$ & 1.47 & 1.45 & $5.00 *$ & 0.76 & 1.50 & 1.11 & 1.04 & 0.50 & 1.00 & & & \\
\hline & Cys & - & - & 1.50 & 5.00 & 1.00 & 3.00 & - & 7.00 & $7.50 *$ & 4.00 & 11.00 & - & - & $7.33^{*}$ & 6.00 & 1.00 & & & & \\
\hline & Gly & 1.61 & $2.10 *$ & 1.27 & 1.06 & - & $6.00 *$ & $2.60 *$ & 2.06 & 2.09 & 2.00 & $5.00 *$ & 1.57 & 2.00 & 1.18 & 1.00 & & & & & \\
\hline & Ala & $2.05^{*}$ & $2.89 *$ & $2.76^{*}$ & 1.94 & 8.00 & 1.59 & 1.59 & $1.83^{*}$ & 1.14 & 2.06 & $5.00 *$ & 1.18 & 1.63 & 1.00 & & & & & & \\
\hline & $\mathrm{His}$ & 1.57 & 1.89 & 0.86 & 1.15 & 4.00 & 4.33 & 1.20 & 1.70 & 0.91 & 2.29 & $3.44^{*}$ & 1.67 & 1.00 & & & & & & & \\
\hline & Met & 1.73 & 1.76 & 1.31 & 2.33 & 3.00 & $2.20 *$ & 1.00 & $2.28^{*}$ & 1.55 & 1.81 & 2.50 & 1.00 & & & & & & & & \\
\hline & Tyr & 0.35 & 0.55 & 0.47 & 0.33 & 1.07 & 0.75 & 0.52 & 0.65 & $0.30+$ & 0.87 & 1.00 & & & & & & & & & \\
\hline & Phe & 0.53 & 0.88 & 1.12 & 0.42 & 1.48 & 1.04 & 0.58 & 0.94 & 0.70 & 1.00 & & & & & & & & & & \\
\hline & Val & 1.15 & $2.05^{*}$ & 0.80 & 1.00 & 4.50 & $1.57^{*}$ & 0.94 & $1.44 *$ & 1.00 & & & & & & & & & & & \\
\hline & Leu & 0.62 & $1.35^{*}$ & 1.04 & 0.61 & 1.80 & $1.32 *$ & 1.03 & 1.00 & & & & & & & & & & & & \\
\hline & Pro & 1.00 & 1.05 & 0.62 & 0.86 & 1.50 & 1.08 & 1.00 & & & & & & & & & & & & & \\
\hline & Ile & 0.66 & 0.84 & 0.76 & 0.53 & $3.25^{*}$ & 1.00 & & & & & & & & & & & & & & \\
\hline & Trp & 0.38 & 1.00 & 0.50 & 1.50 & 1.00 & & & & & & & & & & & & & & & \\
\hline & Asp & 2.21 & I.74* & 1.21 & 1.00 & & & & & & & & & & & & & & & & \\
\hline & Glu & 0.97 & $1.61 *$ & 1.00 & & & & & & & & & & & & & & & & & \\
\hline & Lys & 0.91 & 1.00 & & & & & & & & & & & & & & & & & & \\
\hline & Arg & 1.00 & & & & & & & & & & & & & & & & & & & \\
\hline
\end{tabular}

Each cell in the table is the ratio of replacements for a particular pair of amino acid. * indicates the replacements favored in the mesophilic to thermophilic direction whereas + indicates the opposite direction of such replacements have significant directional bias $(P<0.01)$. 


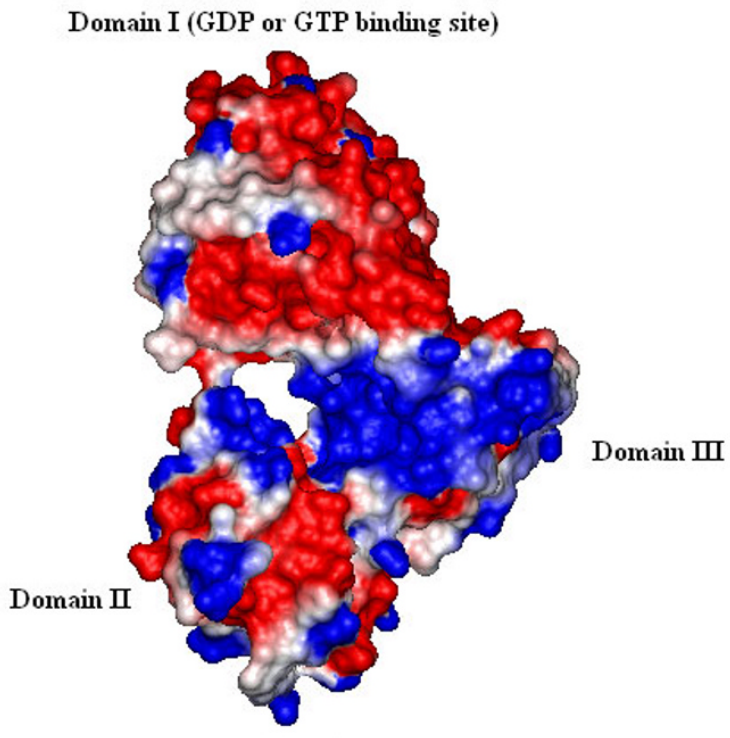

E. coli

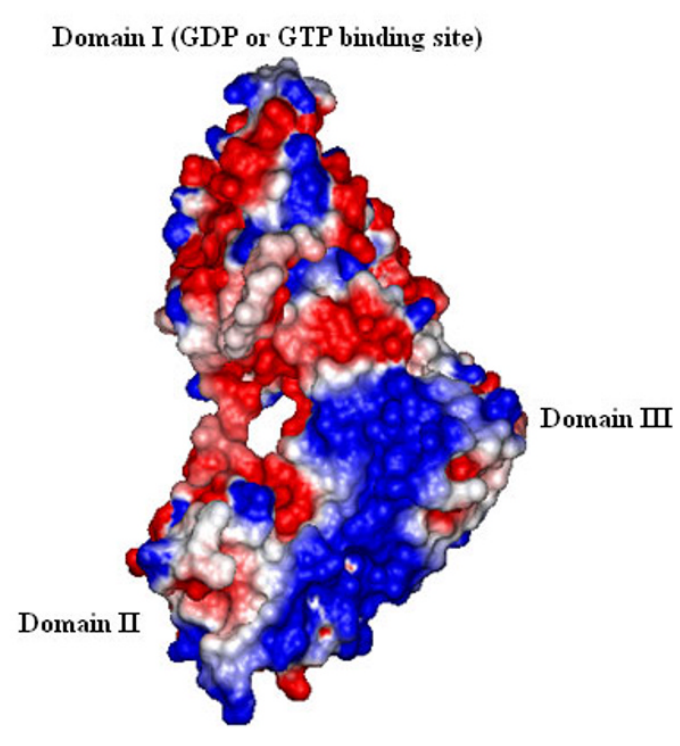

N. equitans

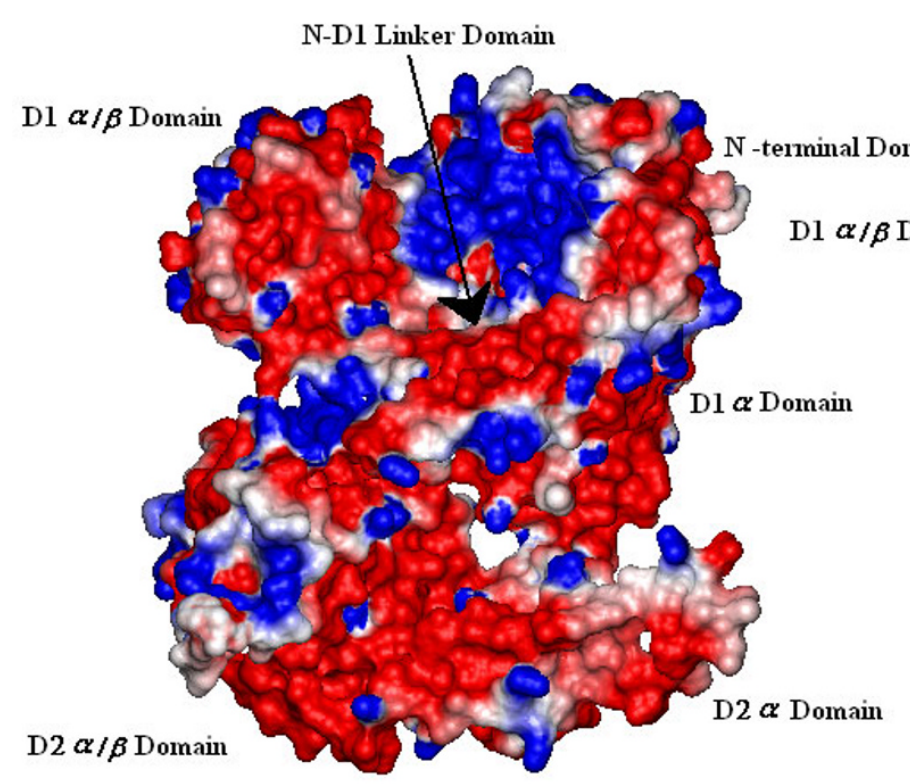

M. maripaludis 
Table 4: Major trends in synonymous codon and amino acid usage, as obtained from COA of RSCU and amino acid usage in genes/ gene-products encoded by $N$. equitans

\begin{tabular}{|c|c|c|c|c|c|c|}
\hline \multirow[b]{2}{*}{ Principal axes } & \multicolumn{3}{|c|}{ Codon usage } & \multicolumn{3}{|c|}{ Amino acid usage } \\
\hline & $\begin{array}{c}\text { Variability } \\
\text { explained (\%) }\end{array}$ & Source of variation & $\begin{array}{l}\text { Correlation } \\
\text { coefficient* }(r- \\
\text { value })\end{array}$ & $\begin{array}{c}\text { Variability } \\
\text { explained (\%) }\end{array}$ & Source of variation & $\begin{array}{c}\text { Correlation } \\
\text { coefficient* }(r- \\
\text { value })\end{array}$ \\
\hline \multirow[t]{3}{*}{ Ist axis } & 7.53 & CAI & 0.42 & 21.25 & Mean Aromaticity & -0.66 \\
\hline & & $\mathrm{N}_{\mathrm{C}}$ & -0.29 & & Gravy score & -0.56 \\
\hline & & $A_{3 S}$ & 0.24 & & CAI & 0.39 \\
\hline \multirow[t]{2}{*}{$2^{\text {nd }}$ axis } & 7.05 & - & - & 13.32 & Aliphatic Index & 0.78 \\
\hline & & & & & Gravy Score & 0.75 \\
\hline \multirow[t]{2}{*}{$3^{\text {rd }}$ axis } & 5.71 & - & - & 11.12 & MMW & 0.80 \\
\hline & & & & & CAI & -0.31 \\
\hline
\end{tabular}

* significant at $\mathrm{p}<0.0001$

encoded proteins of 487 ORFs (Table 4). There are two distinct clusters of genes along the 2nd major axis near the left end of axis 1 (Fig. 5a). The proteins encoded by these two clusters of genes are mainly cell envelope or secreted proteins, which comprise about $15 \%$ of the total predicted proteins under study. The encoded proteins of the upper cluster (UC) genes are significantly over represented ( $p<0.001)$ by Phe, Leu, Ile, Met and Ala, whereas Tyr, Cys, Gln, Thr, Asn, Lys, Asp and Glu are present in sig- nificantly higher amounts $(\mathrm{p}<0.001)$ in the lower cluster (LC) proteins (Table 5). These two groups of proteins also differ in their predicted secondary structures as well as in the content of potential disordered structures. For the members of the UC, propensities for the formation of alpha helix structure (mean value 47.77) are much higher than for the formation of beta sheet (mean value 17.33). On the contrary, the proteins encoded by the LC genes have higher propensities for the formation of beta sheet

Table 5: Comparison of amino acid usage between two clusters of probable membrane associated proteins and between potential highly and lowly expressed genes

\begin{tabular}{|c|c|c|c|c|c|c|c|c|}
\hline \multirow{3}{*}{ Amino acids } & \multicolumn{8}{|c|}{ N. equitans } \\
\hline & \multicolumn{2}{|c|}{ Upper cluster genes } & \multicolumn{2}{|c|}{ Lower cluster genes } & \multicolumn{2}{|c|}{ Highly expressed genes } & \multicolumn{2}{|c|}{ Lowly expressed genes } \\
\hline & Number & (\%) & Number & (\%) & Number & (\%) & Number & (\%) \\
\hline Phe & 771 & $7.88^{*}$ & 649 & 4.20 & 367 & 3.55 & 402 & 5.20 \\
\hline Leu & 1708 & $17.46^{*}$ & 1394 & 9.01 & 954 & 9.24 & 912 & $\mathrm{II} .8 \mathrm{I}$ \\
\hline Ser & 626 & 6.40 & 1060 & 6.85 & 383 & 3.71 & 409 & 5.30 \\
\hline Tyr & 585 & 5.98 & 1117 & $7.22+$ & 429 & 4.15 & 494 & 6.40 \\
\hline Cys & 33 & 0.34 & 424 & $2.74+$ & 46 & 0.45 & 85 & 1.10 \\
\hline Trp & 102 & 1.04 & 137 & 0.89 & 95 & 0.92 & 77 & 1.00 \\
\hline Pro & 329 & 3.36 & 597 & 3.86 & 488 & 4.72 & 314 & 4.07 \\
\hline His & 96 & 0.98 & 118 & 0.76 & 155 & 1.50 & 61 & 0.79 \\
\hline Gln & 155 & 1.58 & 347 & $2.24+$ & 243 & 2.35 & 137 & 1.77 \\
\hline Arg & 178 & 1.82 & 345 & 2.23 & 444 & 4.30 & 204 & 2.64 \\
\hline Ile & 1373 & $14.04 *$ & 1604 & 10.37 & 866 & 8.38 & 940 & 12.17 \\
\hline Met & 190 & $1.94 *$ & 168 & 1.09 & 226 & 2.19 & 128 & 1.66 \\
\hline Thr & 426 & 4.35 & 879 & $5.68+$ & 484 & 4.69 & 311 & 4.03 \\
\hline Asn & 405 & 4.14 & 1384 & $8.95+$ & 446 & 4.32 & 459 & 5.94 \\
\hline Lys & 627 & 6.41 & 1504 & $9.72+$ & 1099 & 10.64 & 840 & 10.88 \\
\hline Val & 571 & 5.84 & 864 & 5.59 & 836 & 8.09 & 389 & 5.04 \\
\hline Ala & 558 & $5.70^{*}$ & 600 & 3.88 & 703 & 6.81 & 344 & 4.45 \\
\hline Asp & 267 & 2.73 & 724 & $4.68+$ & 516 & 5.00 & 327 & 4.23 \\
\hline Glu & 341 & 3.49 & 816 & $5.28+$ & 895 & 8.66 & 508 & 6.58 \\
\hline Gly & $44 I$ & 4.51 & 737 & 4.76 & 655 & 6.34 & 383 & 4.96 \\
\hline
\end{tabular}

Values marked with *or + are significantly $(\mathrm{p}<0.001)$ more frequent in upper or lower cluster gene products respectively and the values in bold faces indicate significant $(\mathrm{p}<0.00 \mathrm{I})$ overrepresentation of corresponding amino acids in potential highly expressed genes. 

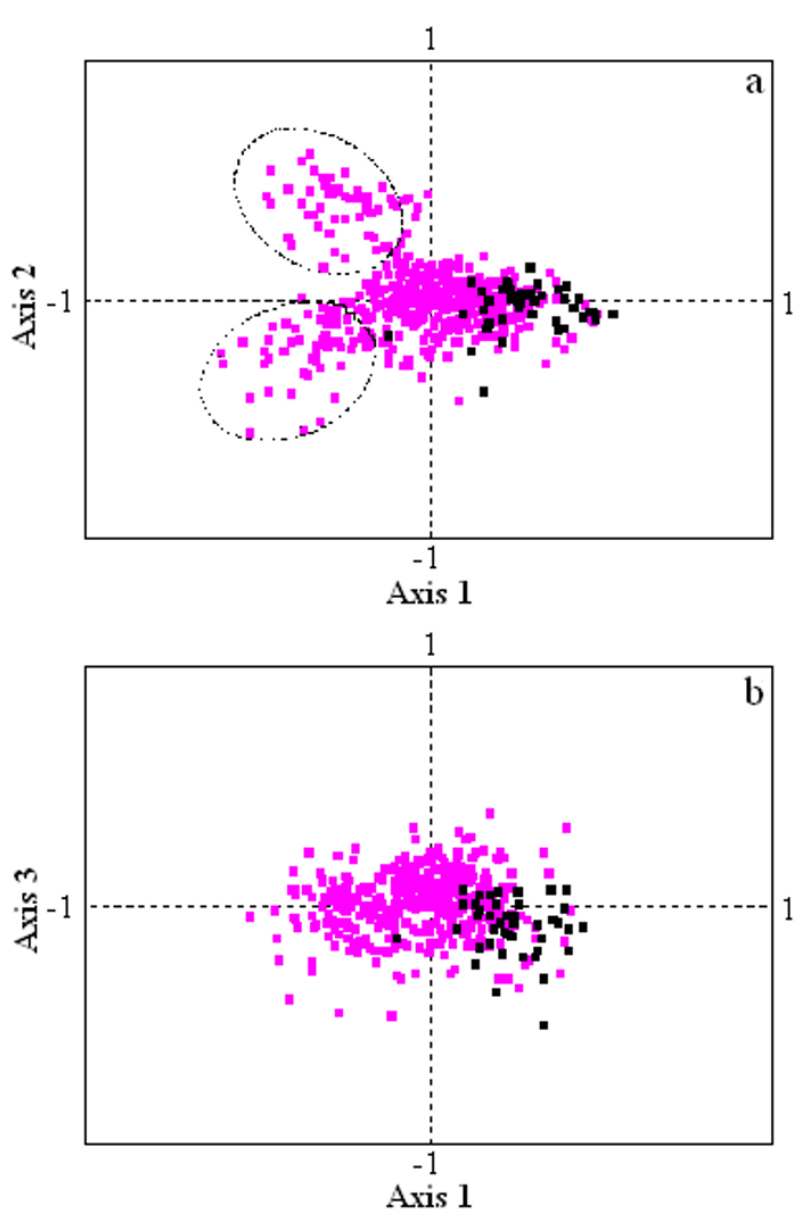

Figure 5

COA on amino acid usage for encoded proteins of $N$. equitans. (a) Position of genes on the plane defined by axis I and axis 2 . The upper and lower clusters of genes mainly encoding membrane-associated proteins are marked by dashed-line ovals. (b) Position of genes on the plane defined by axis I and axis 3. Black quadrangle and pink quadrangle represent highly expressed and other genes respectively.

(mean value 28.70) than alpha helix (mean value 19.74) structure. Furthermore, the proteins encoded by the UC genes have significantly lower propensities for the formation of random coil (mean value 34.90) and putatively have 5-7 transmembrane domains, while the members of LC, in general, show higher propensities for the formation of random coil (mean value 51.56) and are predicted to have only 1-2 transmembrane domains [see Additional file 3]. Disordered regions in proteins can be predicted by the lack of regular secondary structures, whereas ordered regions (often termed globular) typically contain regular secondary structures packed into a compact globule $[37,38]$. In N. equitans, the probable coil forming regions are significantly higher in LC proteins (Table 5); hence, disordered structures are more commonly found in the proteins of LC than in the proteins comprising the UC.

Another important source of intra-proteomic variations in amino acid usage is gene expressivity, as indicated by the presence of potential highly expressed genes near the positive extreme of axis 1 and at the negative extremes of axis 3 (Fig. 5b). Both axes exhibit significant correlation with CAI values of the genes (Table 4). The significant positive correlation of MMW with axis 3 and the negative correlation between axis 1 and aromaticity (Table 4 ) suggest that the potential highly expressed genes in N. equitans have a tendency to avoid the heavier residues including the aromatic ones (Table 5). N. equitans is a strictly host-adapted microorganism, which can exploit the cellular machinery of host organisms for its own survival. It is therefore interesting to note that it follows the cost minimization hypothesis [39], which claims that highly expressed genes tend to use small and energetically less expensive amino acids in their encoded proteins.

\section{Evaluation of hyperthermophilic signature on synonymous codon usage}

In an attempt to examine whether the pattern of synonymous codon usage in $N$. equitans follows the hyperthermophilic signature, COA has been applied on Relative Synonymous Codon Usage (RSCU) of 35056 predicted ORFs of the fifteen microbial genomes under study (enlisted in Table 1). The axis 1- axis 2 plot of the COA on RSCU values exhibits two distinct clusters, the mesophilic and hyperthermophilic (N. equitans being a subset of the latter) genes being segregated along the second axis with little overlap between them (Fig. 6a). This is in accordance with the studies made earlier by Lynn et al. [25]. Axis 1 (representing $16.2 \%$ of total variation) values are highly correlated to the $\mathrm{GC}_{3 S}$ values $\left(\mathrm{r}=-0.93, \mathrm{p}<10^{-7}\right)$, while axis 2 (representing $13.7 \%$ of total variation) values exhibit a significant positive correlation with $R_{3 S}$ (purine content in synonymous third codon position) of the genes $\left(r=0.54, p<10^{-7}\right)$. These observations indicate that the pattern of synonymous codon usage in N. equitans, as with other hyperthermophiles, is different from that observed in the mesophilic microbial organisms, where the usage of purine in third codon positions is comparatively lower.

\section{Intragenomic variation in synonymous codon usage}

To understand the sources of intragenomic variation in codon usage of $N$. equitans we have applied a COA on RSCU of its 487 ORFs. Axis 1 exhibits significant positive correlation with the CAI values of the genes and also exhibits slight but significant positive correlation with $\mathrm{A}_{35}$ (Table 4). Most of the potential highly expressed genes including ribosomal proteins are clustered at the positive extreme of axis 1 (Fig. 6b). In COA on absolute frequen- 

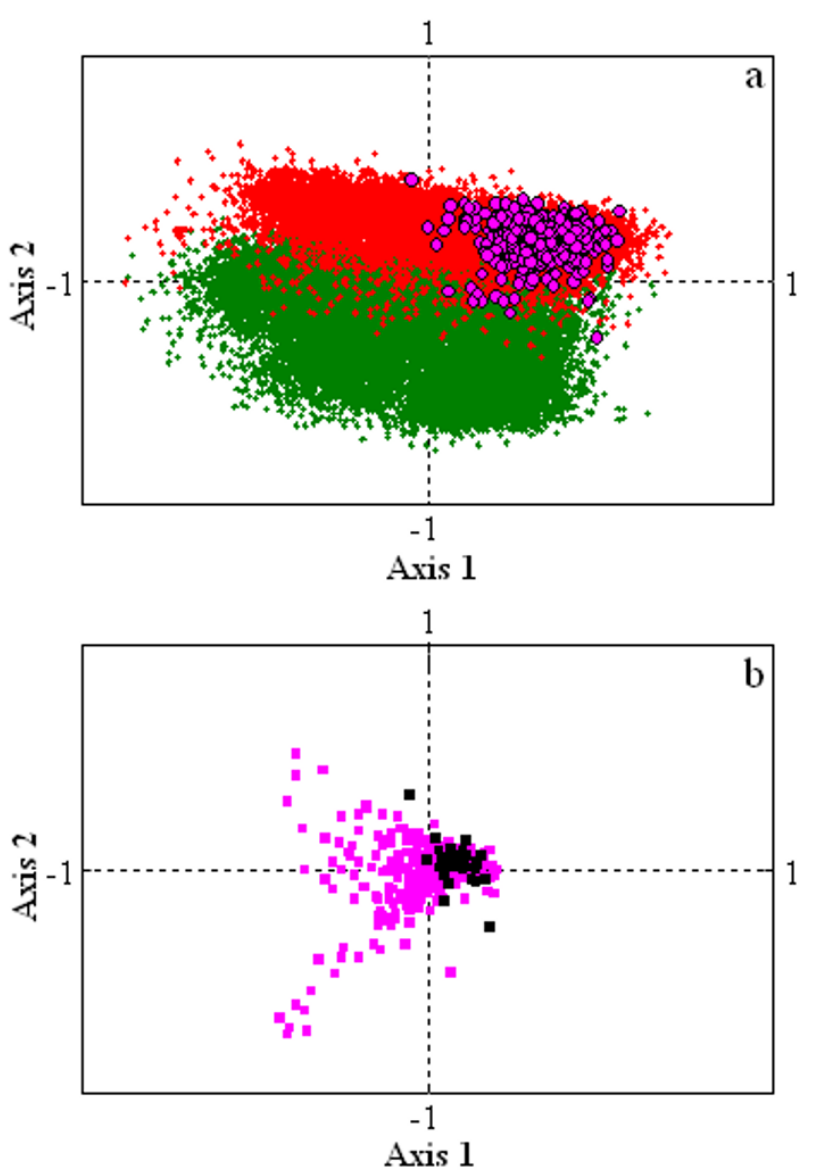

\section{Figure 6}

Position of genes along the first two principal axes generated by COA on RSCU values of (a) 35056 genes from I 5 microbial genomes under study (hyperthermophilic: red dots, mesophilic: green dots, pink circle: N. equitans); (b) 487 genes from $N$. equitans (black quadrangle: potential highly expressed genes, pink quadrangle: the other genes).

cies of synonymous codon usage also, the first major axis (representing $11.5 \%$ of total variation) exhibits significant correlation with CAI values $(\mathrm{r}=-0.52, \mathrm{p}<0.0001)$ and the putative highly expressed genes are clustered on the negative side of that axis. These observations suggest that the major trend in synonymous codon usage is gene expressivity. Usage of 16 codons increases significantly ( $p$ $<0.05$ ) in potential highly expressed genes, most of which prefer to use A-ending or C-ending synonymous codons [see Additional file 2]. However the frequencies of G-ending codons or U-ending codons either remain almost constant in potential highly and lowly expressed genes (except AGG codon for Arg, UGU for Cys and GGU for Gly), or show a marked fall in potential highly expressed genes. Preference for C-ending codons in highly expressed genes against the genome-wide mutational bias is probably a consequence of translational selection [40]. No known parameter of codon usage, base or amino acid composition is found to have significant correlation with the position of sequences on axis 2 (Table 4). But interestingly enough, there is a divergence in the distribution of few genes along axis 2 near the negative extreme of axis 1 . Careful examination reveals that this is only due to the differential usage of four rare synonymous codons (CGN of Arg) in N. equitans.

The synonymous codon bias in the potential highly expressed genes of $N$. equitans may not be very strong, as axis 1 of the COA on RSCU describes a rather small amount of total variation - a situation encountered in most of the obligatory symbiotic/parasitic microbial organisms (Table 6). It is worth mentioning at this point that the strictly host-associated microorganisms are usually characterized by a reduced genome, presence of only one or two rRNA operons, small number of tRNA genes, long generation time, overall AT-richness, and apparently weak translational selection for synonymous codon usage $[11,13]$. The genome of N. equitans is also characterized by massive reduction in size as well as decrease in overall GCcontent, as compared to the free-living hyperthermophilic archaea. It encodes only a limited number of tRNAs (38 identified tRNAs) and single copies of 5S, $16 \mathrm{~S}$ and $23 \mathrm{~S}$ rRNA. The existence of a relatively poor translational selection in N. equitans is, therefore, quite consistent with its parasitic lifestyle.

\section{Discussion}

The present analysis indicates that the dual adaptation of $N$. equitans to high temperature and to an obligate parasitism has imposed selective constraints on nucleotide usage at synonymous and nonsynonymous codon positions, modulating thereby its genome/proteome composition. Thermal adaptation involves overrepresentation of purine bases in protein coding sequences, higher GC-content of the structural RNA genes, enhanced usage of positively charged residues, higher frequencies of aromatic residues, decrease in polar uncharged residues in the encoded protein etc., while parasitic adaptation is reflected in the extreme genome reduction, presence of weak translational selection for synonymous codon usage, limited number of tRNAs and rRNAs, large heterogeneity in membrane associated proteins and so on.

One of the most exciting observations is the significant increase in the usage of positively charged amino acid residues in encoded proteins of $N$. equitans and other hyperthermophiles compared to that in mesophilic organisms. A strong positive correlation between the optimal growth temperature of the organisms and the percentage of proteins with $\mathrm{P} / \mathrm{N}$ ratio $>1$ in the respective proteomes (Fig. $3 \mathrm{~b})$, relatively basic nature of the proteomes of $N$. equitans and other hyperthermophiles, as depicted by isoelectric 
Table 6: Variation in synonymous codon usage in $\mathbf{N}$. equitans and seven other obligatory host- associated microbial organisms

\begin{tabular}{|c|c|c|c|c|c|c|c|}
\hline \multirow[t]{2}{*}{ Organism } & \multirow[t]{2}{*}{ Accession No. } & \multirow[t]{2}{*}{ GC $\%$} & \multirow[t]{2}{*}{$\begin{array}{l}\text { No. of tRNA } \\
\text { genes }\end{array}$} & \multirow[t]{2}{*}{$\begin{array}{l}\text { No. of rRNA } \\
\text { operons }\end{array}$} & \multirow[t]{2}{*}{$\begin{array}{l}\text { ORFs under } \\
\text { study }\end{array}$} & \multicolumn{2}{|c|}{$\begin{array}{c}\text { Variation explained by COA on } \\
\text { RSCU (\%) }\end{array}$} \\
\hline & & & & & & Axis I & Axis2 \\
\hline Buchnera aphidicola & $\mathrm{AE} 013218$ & 26.0 & 30 & 1 & 506 & 7.21 & 5.92 \\
\hline Helicobacter hepaticus & $\underline{A E 017125}$ & 38.0 & 36 & 1 & 1630 & 7.46 & 6.41 \\
\hline Mycoplasma pulmonis & $\underline{A L 445566}$ & 26.6 & 28 & 1 & 705 & 6.96 & 5.97 \\
\hline Nanoarchaeum equitans & AE017199 & 31.6 & 38 & I* & 487 & 7.53 & 7.05 \\
\hline Rickettsia prowazekii & A]235269 & 29.0 & 32 & I & 772 & 6.68 & 5.72 \\
\hline Ureaplasma parvum serovar3 & $\overline{\mathrm{AF} 222894}$ & 25.5 & 29 & 2 & 558 & 7.59 & 7.05 \\
\hline Wigglesworthia glossinidia & BA000021 & 22.5 & 34 & 2 & 575 & 6.42 & 6.16 \\
\hline Wolbachia pipientis & AE017196 & 35.2 & 34 & 1 & 876 & 6.14 & 5.87 \\
\hline
\end{tabular}

* the rRNAs are not in a single operon

point distribution (Fig. 3c) and bias in the replacement of uncharged polar residues of mesophilic proteins by positively charged residues (mainly Lys) in the N. equitans orthologs (Table 3 ) - all point towards a strong preference for positively charged amino acids in the gene-products of hyperthermophiles. In parallel, there has also been an increase in aromatic residues (especially Tyr) in encoded proteins of $N$. equitans and other hyperthermophiles (Fig. 3d; Table 3). Greater involvement of positively charged residues at or near protein surfaces may increase the probability of salt bridge formation with negatively charged residues, while simultaneous increase in aromatic residues may strengthen the cation- $\pi$ interaction. When a cationic side chain comes near an aromatic side chain within a protein, the geometry is known to be biased towards one that would experience a favorable cation- $\pi$ interaction [41]. It was suggested earlier that both salt-bridge and cation- $\pi$ interactions may play important roles in thermostability [42]. Tyrosine, by itself, may also contribute to protein thermostability [43]. Selective increase in Lys/Arg and aromatic residues in N. equitans may, therefore, be a strategy of survival at high temperature. A recent study on atomic simulation has revealed that among the charged residues, Lys has much greater number of accessible rotamers than Arg and may entropically stabilize the folded states of proteins [44].

Marked reduction in the frequencies of uncharged polar residues may also contribute to thermostability by avoiding the deamination and backbone cleavages involving Asn and Gln, which can be catalyzed by Ser and Thr $[45,46]$. According to the Sweet and Eisenberg scale [34], there is a significant increase in average hydrophobicity in the encoded proteins of $N$. equitans, as compared to their mesophilic orthologs. This may also be a part of the measures taken for environmental adaptation. The KyteDoolittle scale [47], however, did not indicate any significant difference in average hydrophobicity between these two groups of proteins. It was suggested earlier by Haney et al. [32] that some of the established hydrophobicity scales are strongly correlated to the differences between the proteins of mesophiles and thermophiles, whereas others are not. Replacement of the uncharged polar residues of mesophilic proteins by more hydrophobic residues in N. equitans orthologs may lead to an increase in the extent of the hydrophobic core and hence to a decrease in the solvent accessible surface area of the protein. Therefore the stability of $N$. equitans proteins in extremely high temperatures is apparently provided by significant modifications in their sequences toward enrichment of certain residues.

It is interesting to note that unlike mesophilic organisms, in $N$. equitans and other hyperthermophiles, there is a markedly differential selection for nucleotide usage in protein coding and structural RNA sequences. Both nonsynonymous and synonymous codon positions of their coding sequences are purine rich, and this has two probable consequences. Firstly, due to purine richness of protein-coding sequences, the organisms may minimize unnecessary RNA-RNA interactions and prevent the double-stranded RNA formation within the molecule [30]. Secondly, the higher purine content in nonsynonymous codon position has good correlation with the increased frequencies of certain residues in the encoded proteins. These may help the organism to adapt in high temperature. In contrast, the structural RNA sequences (tRNAs and rRNAs) of these organisms are characterized by significantly higher GC-content and hence by an increased number of hydrogen bonds, which may facilitate intramolecular stabilization at elevated temperature $[29,48]$. Thus, in N. equitans, selection for the prevalence of purine bases in ORFs and the GC- richness of non-coding RNA sequences may also be the consequence of its hyperthermophilic adaptation.

Recent studies on several microbial genomes indicate a close connection between synonymous codon usage bias, 
tRNA abundance, number of rRNA operons, optimal generation time and genome size $[6,7,49]$. Most of the species with reduced genomes are host-associated microorganisms, characterized by the presence of only one or two rRNA operons, a small number of tRNA genes, long generation time and overall AT-richness. Evidences for apparently little translational selection have been reported in most of these organisms. N. equitans, which is an archaeal parasite with the smallest genome known so far, encodes only a limited number of tRNAs (38 identified tRNAs) and single copies of 5S, $16 \mathrm{~S}$ and 23S rRNA. Although $N$. equitans is a hyperthermophilic archaeon, evidence for a relatively poor translational selection for synonymous codon usage is consistent with the earlier observations on several bacteria adapted to strictly host-associated lifestyle. Furthermore, the synonymous codon usage pattern of $N$. equitans forms a subset of the patterns observed typically in hyperthermophilic microbial species and is quite distinct from the patterns of the mesophilic organisms (Fig. 5a). Synonymous codon usage in Nanoarchaeal genes, therefore, reveals a dual adaptation to obligatory parasitism and hyperthermophilicity.

As demonstrated by the COA on amino acid usage, probable membrane associated proteins exhibit two different clusters (Fig. 4a). The amino acid usage profile and the predicted secondary structures of the members of these two clusters are quite distinct from one another (Table 5). Most of the variations in cell-surface proteins may be potentially important for $N$. equitans to interact with the Ignicoccus host and probably evolved during the course of parasitic and/or thermal adaptation. It is also important to note that in spite of its obligatory parasitic lifestyle, there is a tendency to follow the cost-minimization hypothesis at lower level as proteins encoded by highly expressed genes are preferentially constructed with some smaller and energetically less expensive amino acids. Existence of cost minimization effect in host-associated organisms might be due to a genome-level adaptation to utilize less expensive and small residues from the host in the highly expressed genes $[12,14,50]$. This might have an evolutionary advantage to minimize host energy exhaustion for maintaining continued association and the chance of elimination by the host.

Hyperthermophilic organisms, in general, have comparatively smaller genome than the mesophilic organisms. It might be advantageous in hyperthermophiles to maintain multiple copies of chromosomes per cell due to a probable need of a reserve supply of intact chromosome to compensate for the greater chance of DNA double strand breaks at high temperature [51,52]. Furthermore, the faster replication of small genome is likely to be more favorable in the environment having temperatures near to or above $100^{\circ} \mathrm{C}$ [52]. Many microbial organisms living in close association with other organisms in an obligate symbiotic or parasitic relationship also experienced a reduction in genome size with respect to their free-living ancestors. The N. equitans genome lacks the genes for central metabolism, primary biosynthesis and bioenergetic apparatus [1], which are expected to be present in the common archaeal ancestor. In contrast to mesophilic organisms, it possesses the simplest functional protein folding system - the genome contains only single copies of homologues of prefoldin $\alpha$ - and $\beta$-subunits, Hsp60 and sHsp [52]. Unlike other obligate symbiotic/parasitic organisms, $N$. equitans has well-organized DNA repair mechanism with a full set of archaeal DNA repair and recombination enzymes [1]. Furthermore, despite the small genome size, it devotes a large amount of coding capacity for surface-associated proteins, suggesting that the interaction with its host may play a major part in the parasitic adaptation of the organism. Hence, it can be inferred that the unusual genome reduction and genome composition in N. equitans are the consequences of both hyperthermophilic and parasitic adaptation and during the coevolutionary process with Ignicoccus host, N. equitans may have experienced a dramatic decrease of genome size, retaining only the essential genes for its thermo-parasitic lifestyle.

\section{Conclusion}

Comprehensive analysis on the N. equitans genome along with its comparison to other mesophiles, hyperthermophiles and host-associated organisms allowed us to understand how the dual adaptation of $N$. equitans to high temperature and to an obligate parasitism can influence the nucleotide usage at synonymous and nonsynonymous codon positions, modulating thereby its genome/ proteome composition. Thermal adaptation involves overrepresentation of purine bases in protein coding sequences, higher GC-content of the structural RNAs, enhanced usage of positively charged residues and aromatic residues, decrease in polar uncharged residues in the encoded protein and so on, while the parasitic adaptation is reflected in the extreme genome reduction, presence of weak translational selection for synonymous codon usage, large heterogeneity in membrane associated proteins etc. Our findings not only offer an insight into the mechanisms of genomic adaptation of $N$. equitans to high temperature and parasitism, but also evaluate the generality of such mechanisms in the microbial world.

\section{Methods}

\section{Sequence retrieval}

All predicted protein coding sequences and the sequences of structural RNAs (tRNAs and rRNAs) of Nanoarchaeum equitans Kin4-M were extracted from NCBI GenBank (Version 145.0) [53]. To understand temperature related traits, we compiled sequences of predicted protein coding 
genes and structural RNAs from seven hyperthermophilic and seven mesophilic microbial organisms from GenBank [53]. For comparison purpose, the selection of these completely sequenced microbial organisms was based on the close approximation in genomic GC-content of N. equitans (i.e. all organisms under study are relatively AT-rich) to minimize the GC-compositional effect on codon as well as on amino acid usage. To compare with other hostassociated organisms, sequences from seven obligatory parasitic/symbiotic microorganisms were also retrieved. In order to reduce sampling errors, the annotated genes with less than 100 codons were excluded from the analysis. The presumed duplicates, genes for transposase and integrase, and the genes with internal stop codons and/or untranslatable codons were also excluded.

\section{Base compositional analysis}

To find out the extent of base compositional bias, nucleotide frequency at all three codon positions were calculated for protein coding sequences. The purine content at nonsynonymous codon position $\left(\mathrm{R}_{1+2}\right)$ and synonymous third codon position $\left(R_{3 S}\right)$ were calculated for each coding sequences of seven mesophilic, seven hyperthermophilic organisms and N. equitans. Purine-pyrimidine skew was performed using sliding windows of $0.1 \mathrm{~kb}$ on the genomic sequence of $N$. equitans. The GC content and also purine content of the structural RNA sequences were calculated for $N$. equitans, seven hyperthermophilic and seven mesophilic organisms under study.

\section{Correspondence Analysis on synonymous codon and amino acid usage}

Correspondence Analysis (COA) was performed using the program CODONW 1.4.2 [54] to identify the major factors influencing the variation in relative synonymous codon usage (RSCU) and amino acid frequencies. COA was also carried out on absolute frequencies of synonymous codons in order to avoid introducing other biases [55]. These analyses generate a series of orthogonal axes to identify trends that explain the variation within a dataset, with each subsequent axis explaining a decreasing amount of the variation.

\section{Amino acid exchange bias with orthologous sequences}

Orthologous sequences between $N$. equitans and seven mesophilic organisms under study were taken using the BlastP program [56]. Orthologs were defined as those with more than or equal to $60 \%$ similarities and less than $20 \%$ difference in length. The amino acid sequences of 105 orthologous genes were aligned using the pairwise alignment program (ClustalW) and the amino acid replacements were obtained in the form of a matrix, using a program developed in-house in Visual Basic. For a given pair of amino acids, the "forward" direction exhibited the more common of the two replacements in the conversion of mesophilic proteins to $N$. equitans proteins. To assess the significance of the directional bias, if any, replacement values were compared by $2 \times 2$ contingency tables having 1 degree of freedom. For each pair of replacements, the first and second rows of the contingency table represented the number of replacements from one particular residue (say, i) to another (say, j) of the pair and the total count of the remaining replacements (say, $\mathrm{k}$ ) from the residue $\mathrm{i}$ (where $\mathrm{k} \neq \mathrm{j}$ ) respectively.

\section{Prediction of secondary structure, transmembrane domain and protein disorder}

The prediction of protein secondary structure was performed using GOR IV algorithm [57] and the disordered regions within proteins were predicted using GlobPlot [38]. SMART [58] and TMHMM2.0 [59] available at ExPASy Proteomics Server [60] were used to detect the proteins likely to secreted in or localized to the cell surface.

\section{Indices used to identify the trends in codon and amino acid usage}

Indices like total number of occurrence of each codon, RSCU [61], codon adaptive index (CAI) [61], amino acids frequencies, average hydrophobicity (Gravy score) [34,47], aromaticity [62], aliphatic index [63] and mean molecular weight (MMW) of protein coding sequences were calculated to find out the factors influencing codon and amino acid usage. The CAI was calculated for N. equitans genes with respect to the RSCU values of the genes for ribosomal proteins ( $\geq 100 \mathrm{aa}$ ). The isoelectric point (pI) of each predicted proteins were calculated using Expasy proteomics server [60].

\section{Homology modeling}

Modeled structures were generated for the elongation factor Tu (EF- Tu) of N. equitans and the cell division cycle family protein from both $N$. equitans and M. maripaludis (NEQ475 in N. equitans and MMP0176 in M. maripaludis) by using the First Approach Mode at the Swiss-Model protein structure homology modeling server [64]. The surface charge distributions were mapped onto the predicted surface using the program MOLMOL [65]. Total surface charge was calculated using Biomolecule module in Insight II workstation. Comparisons were made between N. equitans EF- Tu and E. coli EF- Tu (Blast P value $1 e^{-45}$ ) and between the CDC proteins from $N$. equitans (NEQ475) and M. maripaludis (MMP0176) (Blast P value $0.0)$.

\section{Abbreviations}

COA, Correspondence analysis; CAI, Codon adaptation index; OGT, Optimal growth temperature; ORF, Open Reading Frame; $\mathrm{GC}_{3 \mathrm{~S}}$, GC-content at synonymous codon position; $\mathrm{R}_{1+2}$, Purine content at first and second codon 
positions; $\mathrm{R}_{3 S^{\prime}}$ Purine content at synonymous codon position; MMW, Mean molecular weight; RSCU, Relative synonymous codon usage.

\section{Authors' contributions}

SD and SP made substantial contributions to the conception of the study, devised the overall strategy, performed genome sequence analysis and drafted the manuscript. SKB developed relevant programs for sequence analysis and performed sequence alignment. CD participated in the design and coordination of the study and revised the manuscript critically for important intellectual content. All authors read and approved the final manuscript.

\section{Additional material}

\section{Additional file 1}

Amino acid replacement values between $\mathrm{N}$. equitans proteins and their mesophilic orthologs

Click here for file

[http://www.biomedcentral.com/content/supplementary/1471-

2164-7-186-S1.doc]

\section{Additional file 2}

Synonymous codon usage in $\mathrm{N}$. equitans

Click here for file

[http://www.biomedcentral.com/content/supplementary/1471-

2164-7-186-S2.doc]

\section{Additional file 3}

TMHMM plot of the probable membrane associated proteins encoded by genes taken from upper and lower clusters generated by COA on amino acid usage for $\mathrm{N}$. equitans genome. The plots of the left panel are the representatives of upper cluster and those in the right panels are the representatives of lower cluster. Red, blue and pink colours indicate the transmembrane, outside and inside regions of the protein respectively. Click here for file

[http://www.biomedcentral.com/content/supplementary/14712164-7-186-S3.tiff]

\section{Acknowledgements}

We are grateful to Dr. B. Achari, Emeritus Scientist, Indian Institute of Chemical Biology, Kolkata, India, for critical reading of the manuscript. This work was supported by the Council of Scientific and Industrial Research (Project No. CMM 0017) and Department of Biotechnology, Government of India (Grant Number BT/BI/04/055-200I).

\section{References}

I. Waters E, Hohn MJ, Ahel I, Graham DE, Adams MD, Barnstead M, Beeson KY, Bibbs L, Bolanos R, Keller M, et al.: The genome of Nanoarchaeum equitans: insights into early archaeal evolution and derived parasitism. Proc Natl Acad Sci USA 2003, 100: 12984-12988.

2. Huber H, Hohn MJ, Rachel R, Fuchs T, Wimmer VC, Stetter KO: A new phylum of Archaea represented by a nanosized hyperthermophilic symbiont. Nature 2002, 4I 7:63-67.

3. Moran NA: Accelerated evolution and Muller's rachet in endosymbiotic bacteria. Proc Natl Acad Sci USA 1996, 93:2873-2878
4. Moran NA, Wernegreen J]: Lifestyle evolution in symbiotic bacteria: insights from genomics. Trends Ecol Evol (Amst) 2000, I 5:321-326.

5. Osawa S, Ohama T, Yamao F, Muto A, Jukes TH, Ozeki H, Umesono $\mathrm{K}$ : Directional mutation pressure and transfer RNA in choice of the third nucleotide of synonymous two-codon sets. Proc Natl Acad Sci USA 1988, 85: I I 24- I I 28.

6. Rocha EP: Codon usage bias from tRNA's point of view: redundancy, specialization, and efficient decoding for translation optimization. Genome Res 2004, I 4:2279-2286.

7. Sharp PM, Bailes E, Grocock RJ, Peden JF, Sockett RE: Variation in the strength of selected codon usage bias among bacteria. Nucleic Acids Res 2005, 33: I I 4 I- I I 53.

8. Gil R, Silva FJ, Zientz E, Delmotte F, Gonzalez-Candelas F, Latorre A, Rausell C, Kamerbeek J, Gadau J, Holldobler B, et al.: The genome sequence of Blochmannia floridanus: comparative analysis of reduced genomes. Proc Natl Acad Sci USA 2003, I 00:9388-9393.

9. Mclnerney JO: Replicational and transcriptional selection on codon usage in Borrelia burgdorferi. Proc Natl Acad Sci USA 1998, 95: 10698-10703.

10. Rispe C, Delmotte F, van Ham RC, Moya A: Mutational and selective pressures on codon and amino acid usage in Buchnera, endosymbiotic bacteria of aphids. Genome Res 2004, 14:44-53.

II. Lafay B, Atherton JC, Sharp PM: Absence of translationally selected synonymous codon usage bias in Helicobacter pylori. Microbiology 2000, I46(Pt 4):85I-860.

12. Das S, Paul S, Chatterjee S, Dutta C: Codon and amino Acid usage in two major human pathogens of genus Bartonella optimization between replicational-transcriptional selection, translational control and cost minimization. DNA Res 2005, I 2:91-102.

13. Herbeck JT, Wall DP, Wernegreen JJ: Gene expression level influences amino acid usage, but not codon usage, in the tsetse fly endosymbiont Wigglesworthia. Microbiology 2003 , I 49:2585-2596

14. Das S, Paul S, Dutta C: Evolutionary constraints on codon and amino acid usage in two strains of human pathogenic actinobacteria Tropheryma whipplei. J Mol Evol 2006, 62:645-658.

15. Singer GA, Hickey DA: Thermophilic prokaryotes have characteristic patterns of codon usage, amino acid composition and nucleotide content. Gene 2003, 3 I 7:39-47.

16. Berezovsky IN, Tumanyan VG, Esipova NG: Representation of amino acid sequences in terms of interaction energy in protein globules. FEBS Lett 1997, 41 8:43-46.

17. Kumar S, Tsai C], Nussinov R: Factors enhancing protein thermostability. Protein Eng 2000, I3:I79-191.

18. Querol E, Perez-Pons JA, Mozo-Villarias A: Analysis of protein conformational characteristics related to thermostability. Protein Eng 1996, 9:265-271.

19. Schumann J, Bohm G, Schumacher G, Rudolph R, Jaenicke R: Stabilization of creatinase from Pseudomonas putida by random mutagenesis. Protein Sci 1993, 2:1612-1620.

20. Jaenicke R, Bohm G: The stability of proteins in extreme environments. Curr Opin Struct Biol I 998, 8:738-748.

21. Vetriani C, Maeder DL, Tolliday N, Yip KS, Stillman TJ, Britton KL, Rice DW, Klump HH, Robb FT: Protein thermostability above 100 degreesC: a key role for ionic interactions. Proc Natl Acad Sci USA 1998, 95:12300-12305.

22. Hurley TD, Weiner $\mathrm{H}$ : Crystallization and preliminary X-ray investigation of bovine liver mitochondrial aldehyde dehydrogenase. J Mol Biol 1992, 227: I255-I257.

23. Thompson MJ, Eisenberg D: Transproteomic evidence of a loopdeletion mechanism for enhancing protein thermostability. J Mol Biol 1999, 290:595-604.

24. Lambros RJ, Mortimer JR, Forsdyke DR: Optimum growth temperature and the base composition of open reading frames in prokaryotes. Extremophiles 2003, 7:443-450.

25. Lynn DJ, Singer GA, Hickey DA: Synonymous codon usage is subject to selection in thermophilic bacteria. Nucleic Acids Res 2002, 30:4272-4277.

26. Galtier N, Lobry JR: Relationships between genomic G+C content, RNA secondary structures, and optimal growth temperature in prokaryotes. J Mol Evol 1997, 44:632-636.

27. Kawashima T, Amano N, Koike H, Makino S, Higuchi S, KawashimaOhya Y, Watanabe K, Yamazaki M, Kanehori K, Kawamoto T, et al. Archaeal adaptation to higher temperatures revealed by 
genomic sequence of Thermoplasma volcanium. Proc Natl Acad Sci USA 2000, 97: | $4257-14262$.

28. Hurst LD, Merchant AR: High guanine-cytosine content is not an adaptation to high temperature: a comparative analysis amongst prokaryotes. Proc Biol Sci 200I, 268:493-497.

29. Wang HC, Hickey DA: Evidence for strong selective constraint acting on the nucleotide composition of I6S ribosomal RNA genes. Nucleic Acids Res 2002, 30:250I-2507.

30. Paz A, Mester D, Baca I, Nevo E, Korol A: Adaptive role of increased frequency of polypurine tracts in mRNA sequences of thermophilic prokaryotes. Proc Natl Acad Sci USA 2004, I 0I:295I-2956.

31. Kreil DP, Ouzounis CA: Identification of thermophilic species by the amino acid compositions deduced from their genomes. Nucleic Acids Res 200I, 29:1608-1615.

32. Haney PJ, Badger JH, Buldak GL, Reich Cl, Woese CR, Olsen GJ: Thermal adaptation analyzed by comparison of protein sequences from mesophilic and extremely thermophilic Methanococcus species. Proc Natl Acad Sci USA 1999 , 96:3578-3583

33. Nakashima H, Fukuchi S, Nishikawa K: Compositional changes in RNA, DNA and proteins for bacterial adaptation to higher and lower temperatures. J Biochem 2003, |33:507-5 I3.

34. Sweet RM, Eisenberg D: Correlation of sequence hydrophobicities measures similarity in three-dimensional protein structure. I Mol Biol 1983, 171:479-488.

35. Henikoff S, Henikoff JG: Amino acid substitution matrices from protein blocks. Proc Natl Acad Sci USA 1992, 89:109| 5-109|9.

36. Song $H$, Parsons MR, Rowsell S, Leonard G, Phillips SE: Crystal structure of intact elongation factor EF-Tu from Escherichic coli in GDP conformation at 2.05 A resolution. J Mol Biol 1999 , 285: $1245-1256$

37. Fuxreiter M, Simon I, Friedrich P, Tompa P: Preformed structural elements feature in partner recognition by intrinsically unstructured proteins. J Mol Biol 2004, 338:1015-1026.

38. Linding R, Russell RB, Neduva V, Gibson TJ: GlobPlot: Exploring protein sequences for globularity and disorder. Nucleic Acids Res 2003, 31:370I-3708.

39. Seligmann $\mathrm{H}$ : Cost-minimization of amino acid usage. J Mol Evol 2003, 56:|5|-|6|

40. Das S, Ghosh S, Pan A, Dutta C: Compositional variation in bacterial genes and proteins with potential expression level. FEBS Lett 2005, 579:5205-5210.

4I. Gallivan JP, Dougherty DA: Cation-pi interactions in structural biology. Proc Natl Acad Sci USA 1999, 96:9459-9464.

42. Robinson-Rechavi M, Alibes A, Godzik A: Contribution of Electrostatic Interactions, Compactness and Quaternary Structure to Protein Thermostability: Lessons from Structural Genomics of Thermotoga maritima. J Mol Biol 2006, 356:547-557.

43. Gromiha MM: Important inter-residue contacts for enhancing the thermal stability of thermophilic proteins. Biophys Chem 200I, 91:7I-77.

44. Berezovsky IN, Chen WW, Choi PJ, Shakhnovich El: Entropic stabilization of proteins and its proteomic consequences. PLoS Comput Biol 2005, I:e47.

45. Jaenicke R, Bohm G: Thermostability of proteins from Thermotoga maritima. Meth Enzymol 200I, 334:438-469.

46. Vieille C, Epting KL, Kelly RM, Zeikus JG: Bivalent cations and amino-acid composition contribute to the thermostability of Bacillus licheniformis xylose isomerase. Eur J Biochem 200I, 268:629I-630I.

47. Kyte J, Doolittle RF: A simple method for displaying the hydropathic character of a protein. J Mol Biol 1982, I57:105-132.

48. Wada A, Suyama A: Local stability of DNA and RNA secondary structure and its relation to biological functions. Prog Biophys Mol Biol 1986, 47: I I3-157.

49. dos Reis M, Savva R, Wernisch L: Solving the riddle of codon usage preferences: a test for translational selection. Nucleic Acids Res 2004, 32:5036-5044.

50. Peixoto L, Fernandez $\mathrm{V}$, Musto $\mathrm{H}$ : The effect of expression levels on codon usage in Plasmodium falciparum. Parasitology 2004, | 28:245-25|.

51. Bernander R: Chromosome replication, nucleoid segregation and cell division in archaea. Trends Microbiol 2000, 8:278-283.
52. Laksanalamai P, Whitehead TA, Robb FT: Minimal protein-folding systems in hyperthermophilic archaea. Nat Rev Microbiol 2004, 2:315-324.

53. National Centre for Biotechnology Information [http:// www.ncbi.nlm.nih.gov/]

54. Program CODONW I.4.2 [http://molbiol.ox.ac.uk/ win95.codonW.zip]

55. Perriere G, Thioulouse J: Use and misuse of correspondence analysis in codon usage studies. Nucleic Acids Res 2002, 30:4548-4555.

56. Altschul SF, Madden TL, Schaffer AA, Zhang J, Zhang Z, Miller W, Lipman D]: Gapped BLAST and PSI-BLAST: a new generation of protein database search programs. Nucleic Acids Res 1997, 25:3389-3402.

57. Garnier J, Gibrat JF, Robson B: GOR method for predicting protein secondary structure from amino acid sequence. Meth Enzymol 1996, 266:540-553.

58. Schultz J, Milpetz F, Bork P, Ponting CP: SMART, a simple modular architecture research tool: identification of signaling domains. Proc Natl Acad Sci USA 1998, 95:5857-5864.

59. Krogh A, Larsson B, von Heijne G, Sonnhammer EL: Predicting transmembrane protein topology with a hidden Markov model: application to complete genomes. I Mol Biol 200I, 305:567-580.

60. ExPASy Proteomics Server [http://www.expasy.org/]

61. Sharp PM, Li WH: The codon Adaptation Index - a measure of directional synonymous codon usage bias, and its potential applications. Nucleic Acids Res 1987, I 5: I 28I-1295.

62. Lobry JR, Gautier C: Hydrophobicity, expressivity and aromaticity are the major trends of amino-acid usage in 999 Escherichia coli chromosome-encoded genes. Nucleic Acids Res 1994, 22:3174-3180.

63. Ikai $A$ : Thermostability and aliphatic index of globular proteins. Biochem 1980, 88:1895-1898.

64. SWISS-MODEL at ExPASy [http://swissmodel.expasy.org/]

65. Koradi R, Billeter M, Wuthrich K: MOLMOL: a program for display and analysis of macromolecular structures. I Mol Graph 1996, 14:51-55. 29-32
Publish with Bio Med Central and every scientist can read your work free of charge

"BioMed Central will be the most significant development for disseminating the results of biomedical research in our lifetime. "

Sir Paul Nurse, Cancer Research UK

Your research papers will be:

- available free of charge to the entire biomedical community

- peer reviewed and published immediately upon acceptance

- cited in PubMed and archived on PubMed Central

- yours - you keep the copyright

Submit your manuscript here:

http://www.biomedcentral.com/info/publishing_adv.asp
BiolMedcentral 